\title{
DEVELOPMENT OF MICRO CONTROLLER-BASED MONITORING SYSTEM FOR A STAND-ALONE PHOTOVOLTAIC SYSTEM
}

\author{
Y. Y. Agawa1,* and S. B. Ibrahim² \\ 1, 2 Department of Electrical EngineERING, Bayero University Kano, Kano State. NIGERIA \\ Email addresses: ${ }^{1}$ yunusayusufagawa@gmail.com, ${ }^{2}$ sabkibr@yahoo.com
}

\begin{abstract}
Photovoltaic (PV) system performance highly depends on meteorological parameters and, to reduce frequent maintenance and avoid PV system failure, the meteorological and electrical parameters of the system need to be monitored. This paper is on the development of a simple, reliable and high precision photovoltaic monitoring system, which obtains PV system parameters (i.e. PV panel temperature, irradiance, PV battery voltage, ambient temperature and humidity and PV system load current) in real time, display and store the parameters in personal computer. The system uses electronic sensors to obtain the PV system parameters, which are then processed by a microcontroller with Arduino Board and the parameters displayed in personal computer. Clanguage was used for the microcontroller programming. From the experimental results obtained from the work, it shows that the parameters obtained using the developed systems have good correlations with those obtained using standard commercial instruments used in meteorological stations and laboratory for measurements of the same parameters. The mean bias error of the parameters obtained using the developed system to those obtained using meteorological/laboratory instruments are $0.043 \%, 0.0412 \%,-0.297 \%$ and $0.024 \%$ for solar radiation intensity, temperature, humidity and PV battery voltage measurements respectively. The research would provide PV endusers with important information that will be useful in improving PV system performance by reducing frequency of maintenance and also avoid PV system failure.
\end{abstract}

Keywords: Photovoltaic (PV), monitoring, sensors, meteorological and parameters

\section{INTRODUCTION}

Photovoltaic (PV) monitoring is an important issue as the world broadens its portfolio of power options to meet growing energy demands and increasingly stringent environmental concerns; solar power is emerging as an attractive option. Of all the routes for conversion of solar into useful energy, direct conversion of sunlight to electricity through solar PV technology is well accepted. Solar PV has been recognized as an important route for generation of substantial quantities of power by utilizing the light energy from solar radiation.

Accurate and consistent evaluations of PV system performance are critical for the continuing development of the PV industry. For component manufacturers, performance evaluations are benchmarks of quality for existing products. For research and development teams, they are a key metric for helping to identify future needs. For systems integrators and end customers, they are vital tools for evaluating products and product quality to guide future decision-making. As the industry has grown, a clear need has arisen for greater use of and education about appropriate industry standard performance parameters for PV systems. These performance parameters allow the detection of operational problems; facilitate the comparison of systems that may differ with respect to design, technology, or geographic location; and validate models for system performance estimation during the design phase [1].

PV monitoring systems are required to record a vast number of parameters based on IEC617247 standard. Some of the parameters to be recorded include temperature, humidity, irradiance, voltage and load current.

When a PV panel is placed on a roof top, the solar module will heat up, resulting in its temperature 
raising to up to $80^{\circ} \mathrm{C}$ depending on whether air gaps are present between the panel and the roof to exploit natural ventilation, also when the temperature of the PV battery bank exceeds certain degrees it would affect the life span of the battery, so temperature monitoring and control need to be associated with PV system for better performance.

Higher levels of irradiance will cause more electrons to flow from the PV panel [2]. The amount of voltage produced by the $\mathrm{PV}$ panel is affected by the irradiance value. A PV panel voltage output is primarily affected by temperature. The relationship between panel voltage and temperature is actually an inverse one, as the panel temperature increases, the voltage value decreases and vice versa [3].

Presence of water or moisture content due to dew formation on the PV battery bank, would result in short circuit of the battery terminals and it will lead to deposition of some chemical on the battery terminals, this bring the need to monitor and control the humidity in the PV system power bank [4].

Because of the foregoing reasons and the need for optimum utilization of solar energy as electricity source, the monitoring of PV parameters becomes essential [5].

The objective of this study is to develop a microcontroller-based PV monitoring system with easy-to-obtain hardware, flexible that meets the accuracy requirements established by the IEC61724 standard related to photovoltaic monitoring systems This study uses set of electronic sensors which are interfaced with Atmega328 microcontroller with Arduino Board to obtain the PV system parameters (i.e. PV panel temperature, irradiance, PV battery voltage, temperature, humidity and load current) in real time and to display and store the parameters in personal computer.

\section{LITERATURE REVIEW}

Different technologies and mechanisms for PV monitoring exist, which depend on the availability of materials, method and needs of the researcher [6].

Based on surveyed literature, the fundamental components associated with typical PV monitoring system are:
a) Sensors/Data Acquisition systems
b) Controller
c) Display

\subsection{Sensors/Data Acquisition Systems}

Sensors are electronic devices that are used to obtain physical information of a parameter of interest and convert it into electrical signal. In typical PV monitoring systems, electronic sensors are used to obtain parameters that are required for the monitoring system, these parameters which include irradiance, temperature, humidity, voltage and current etc.

\subsubsection{Irradiance Sensing}

The in-plane irradiance is measured in the same plane as the photovoltaic array by means of the calibrated reference devices or light dependent resistor (LDR), photo resistor or photocell [7]. Another sensor for measuring irradiance is pyranometer, a pyranometer is used for measuring solar irradiance on a planar surface and it is designed to measure the solar radiation flux density $\left(\mathrm{W} / \mathrm{m}^{2}\right)$ from the hemisphere above within a wavelength.

\subsubsection{Temperature Sensing}

The PV module temperatures are measured at a location that is representative of the array conditions, using temperature sensors located in the photovoltaic station. The temperature of PV system can be measured using electronic sensors, such as thermistor or LM35 sensor depending on the need of the design, in which the sensor would be placed at the PV module or PV power bank side [8]. But LM35 sensor is more of use, it has been utilized to measure the temperature of solar energy installation because of its advantage of high precision integrated circuit with output voltage of the sensor that is linearly proportional to the Celsius temperature and it does not require any external calibration. The accuracy of these temperature sensors, including signal conditioning, must be greater than $1^{\circ} \mathrm{C}$ in order to determine the temperature of the reference cell or the reference modules [9].

\subsubsection{Humidity Sensing}

The presence of high humidity on the solar cell of the PV module will lead to decrease in electricity that could be produced at the output of solar module [10]. Different sensors such as digital weather meter, electronic capacitor sensor LM331, STH10 sensor etc are used to measure the relative humidity of the PV system; the sensors are placed at the PV module or power bank side to obtain the humidity of the PV system. 


\subsubsection{Voltage and Current Sensing}

The voltage and current parameters may be either direct current (DC) or alternating current (AC). The accuracy of the voltage and current sensors, including signal conditioning, must be greater than $1 \%$. The two main methods of measuring current consist of using shunts or current transducers. The use of shunts is very simple and does not require an extra power supply but does require a high sample rate monitoring for measuring AC [11].

The use of current transducers requires a power supply and can measure both AC and DC [12]. Similarly, the voltage transducer or voltage dividers can be used to measure the DC voltage. The cost will be higher for the voltage transducer [13].

\subsection{Controller}

In every monitoring system, controller plays vital roles of handling the data from the sensor to end users. Hence, a proper selection of the controller is of paramount importance. In past research works, monitoring was usually done by using microcontroller or data acquisition card module. Even though data acquisition card or module are more expensive compared to microcontroller, they are easier to program and have been used in many reported systems [14]. For microcontroller, the resolution of the Analog to Digital converter (ADC) is usually an important factor, as it can influence the accuracy of the monitored data.

The microcontroller receive acquired analog signal from the sensors, convert it to digital and transmit this digital signal to a serial level converter for serial transmission to the personal computer through serial port and receive using HyperTerminal program for display and logging.

LabView is a software package that provides the functional tools and user interface for data acquisition, LabView plays a vital role in data acquisition process. The real time display of the data is possible with the aid of LabView software and also capable of storing, processing, and displaying the collected data [15]. In most cases, one or more sensors transmit analogue readings to the data acquisition card in the computer. These analogue data are then converted to individual digital values and are made available to LabView, at which point they can be displayed to the user [16].

\subsection{Display}

To add value to a monitoring system, a PC-based display feature for monitoring is added to the system, this allows users to observe real time data of the monitoring parameters. Program is developed in personal computer for visual display of the collected data, and further analysis such as graphical presentation of the data and data stored for a record purpose [17].

\subsection{Review of Existing Systems}

[18] presented an Integrated Data-Acquisition for Renewable Sources System Monitoring; a set of sensors were used for measuring both meteorological data and electrical parameters (i.e. temperature, humidity, voltage and current) of the PV system. LabView program was used to further process, display and store the collected data in the PC disk. This system has advantages of rapid development and flexibility and can be easily used for controlling the renewable energy system operation.

Fuentes, et al [19] developed a microcontroller-based data acquisition system for remote PV plant. The measurement system uses a silicon-cell pyranometer as a solar radiation sensor. The data obtained from the sensor was passed to an internal A/D converter of the microcontroller and stored in a serial I2C EEPROM and then uploaded to a portable computer. The results showed that the logical operation of the system was clear.

The implementation of a web-based wireless monitoring system for grid-connected PV converter was undertaken [20]. The study obtained solar radiation, temperature, PV voltage, PV current, grid voltage and grid current using data acquisition method which consists of different electronics sensors. Implementation results showed that the system was able to function with good performance.

Pietruszko and Gradzki [21] developed a PV system that comprised of data acquisition system, Zigbee and RS-232 communication modules and computer that permits user to collect data wirelessly. PIC16F877 type of microcontroller was used; RS-232 makes a bridge of communication between host computer and data acquisition modules. The host computer contains some software that allow collecting data and creating chart, the result obtained by the authors showed that the system was reliable and has low maintenance cost compared to other PV monitoring systems.

In future, research in photovoltaic monitoring system would be to obtain both the PV panel and PV battery metrological and electrical parameters wirelessly and provide a user-friendly Web interface to download, browse, share, and organize data. 


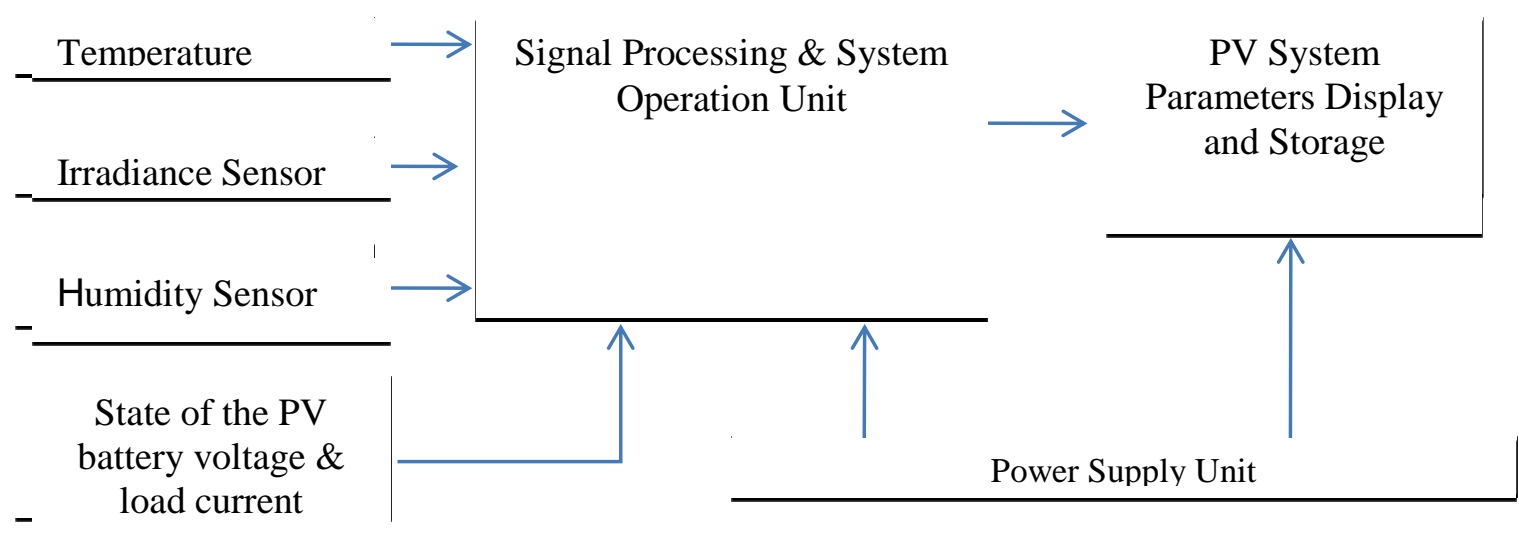

Fig. 1: Block Diagram of the Microcontroller-Based Photovoltaic Monitoring System

In addition, this will provide a Web service application layer to be used to develop customized Web pages for presenting PV power system information to computer users with advantages of low-cost and low power consumption.

\section{METHODS AND MATERIALS}

The proposed PV monitoring system consists of a microcontroller Atmega328, voltage sensing circuit (voltage divider), current sensing circuit LTC6101, temperature sensor LM35, humidity sensor DTH11, irradiation sensor (light dependant resistor), analogto-digital converter circuit, and serially interfaced personal computer. Fig.1 shows the block diagram of the developed PV monitoring system.

The microcontroller program is developed using Arduino package software. This program is written in C language. The parameters obtained from the developed system are collected with the aid of sensors that are interfaced with the microcontroller unit and transferred to personal computer via a serial/USB cable.

The sensors obtain the PV system parameters, namely; PV panel and battery temperatures, battery humidity and PV irradiance, while the voltage and current sensing circuit obtain the electrical parameters (load current and battery voltage) of the PV battery. Once the different sensor signals are obtained and processed by the microcontroller, the data is then sent serially to the PC for display and storage.

The flowchart for the system starts with microcontroller peripheral initialization, then the flowchart proceeds by the scanning of the various sensors reading and storing them in its RAM and transmits this data to the computer via the serial interfacing, as depicted in the Algorithm shown in Fig. 2 .
After developing the microcontroller program, the prototype of the system was assembled in order to carry out experimental test. Fig. 3 shows the developed system prototype, while Fig. 4, 5, and 6 shows the experimental set up.

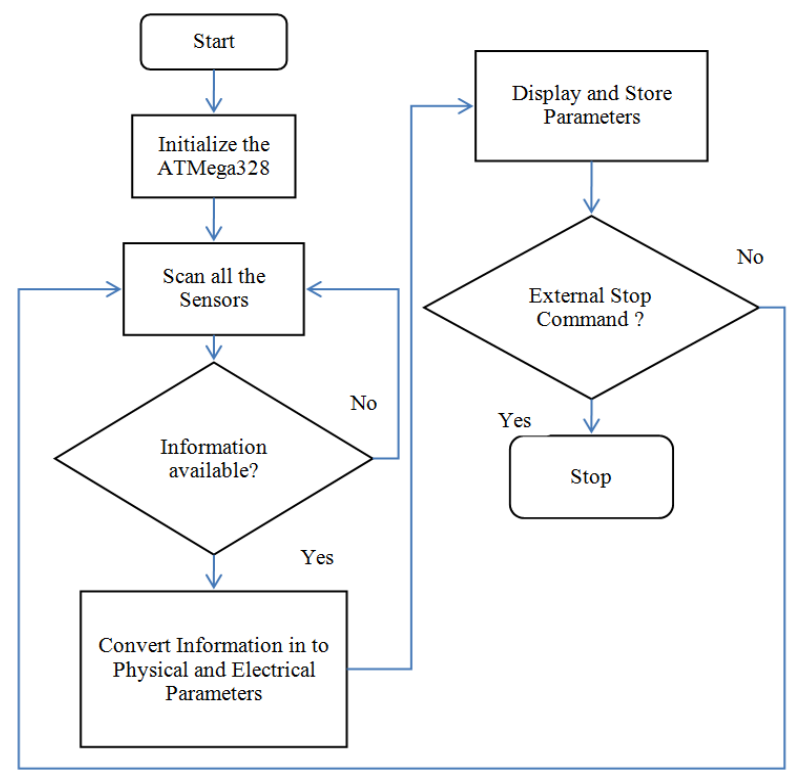

Fig. 2: Flowchart for the PV Monitoring System

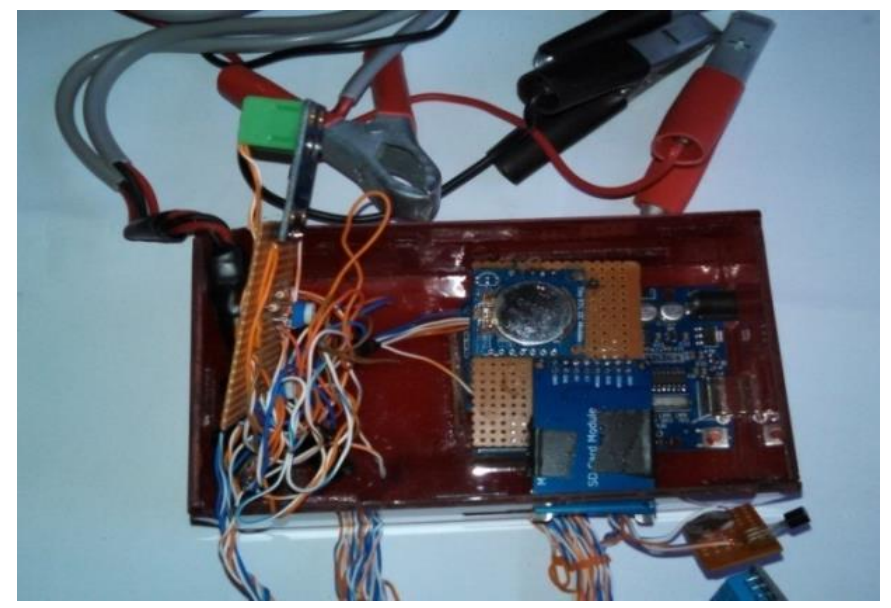

Fig. 3: Developed PV Monitoring System Prototype 


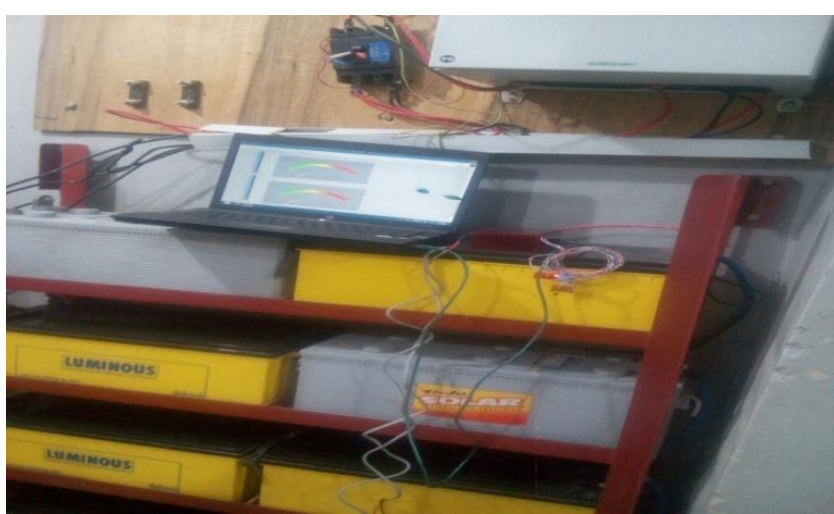

Fig. 4: Monitoring System Connected to PV Power Bank

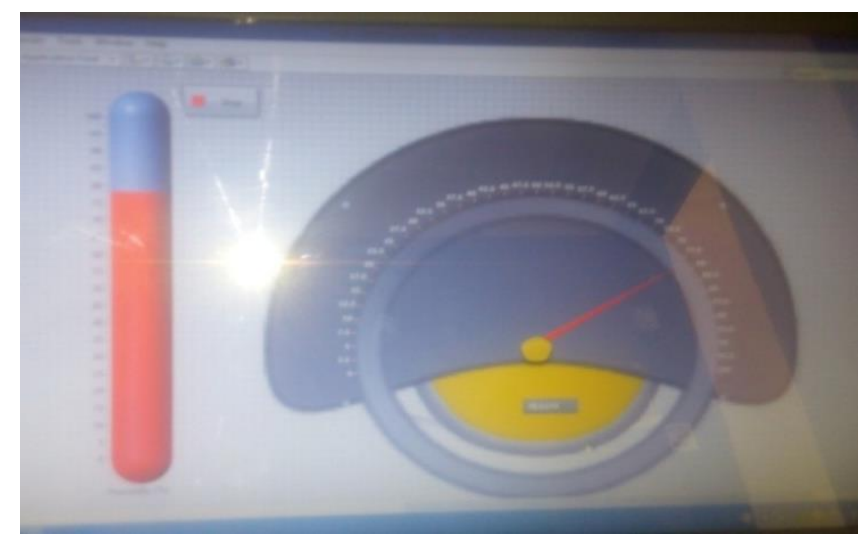

Fig.5a: Humidity Measurement using the Developed System

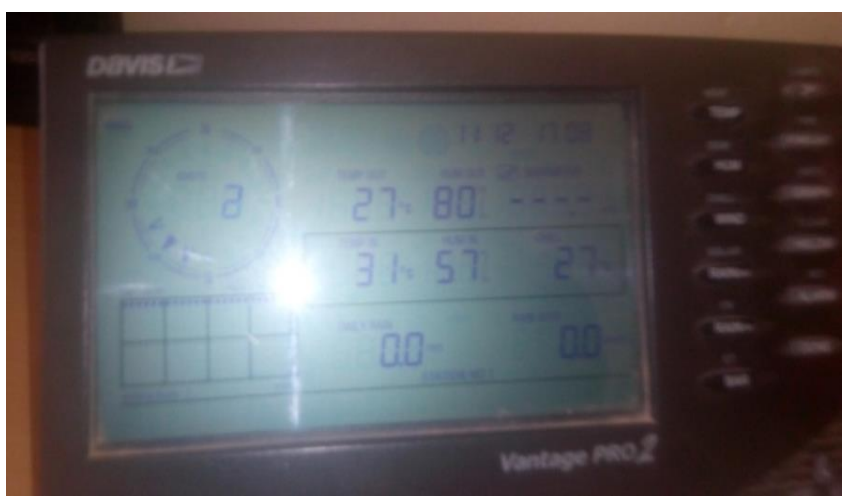

Fig.5b: Humidity Measurement using Meteorological Station Instrument

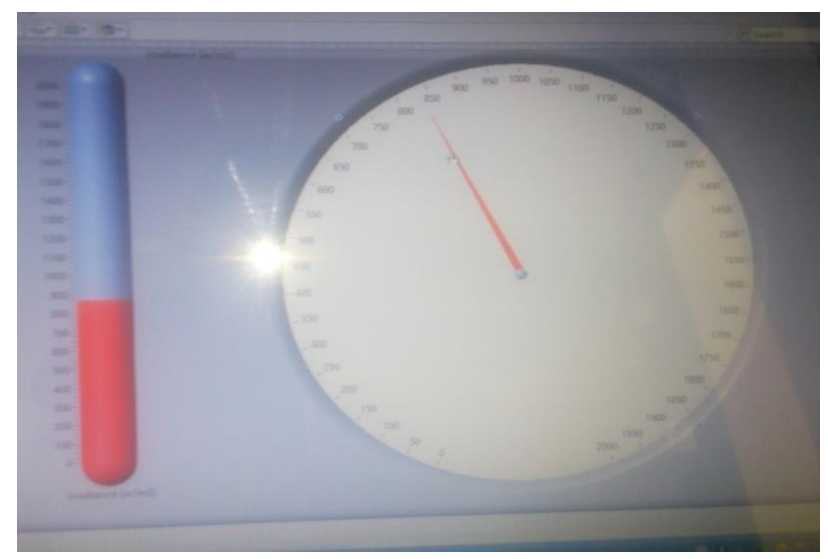

Fig.6a: Irradiance Measurement using the Developed System

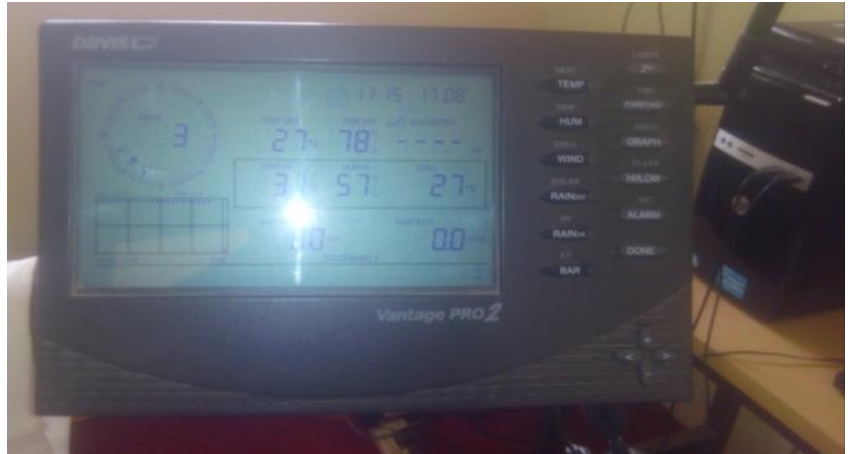

Fig.6b: Irradiance Measurement using Meteorological Station Instrument

\section{RESULTS AND DISCUSSIONS}

The experimental test was conducted with a view to demonstrating the performance of the developed system in relation to that of standard commercial weather station and laboratory instruments and to validate the accuracy of the results obtained from the developed system. Fig.7 shows a one-day irradiance profile using the developed system and that of meteorological station located at Bauchi, Nigeria (Long 10.28164; Lat 9.79096) on 21st March, 2016 from 6:00am to $6: 00 \mathrm{pm}$ which happens to be a sunny day.

Fig. 7 shows solar radiation intensity measured by the developed system and that of meteorological station instrument, which illustrates that the data obtained from the developed system fit well to that obtained from meteorological station instrument, with minimal dispersion.

After demonstrating the good correlation of the results obtained using the developed system in relation to measurements obtained from meteorological station for irradiance measurement, the system also measured and compares temperature, humidity, voltage and current measurements with that obtained from meteorological/laboratory instruments.

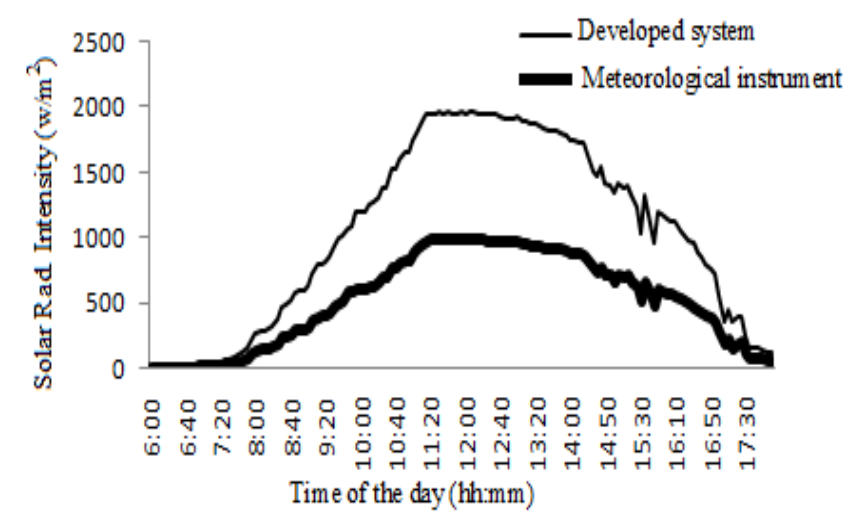

Fig. 7: One-day Solar Radiation Intensity Measured by the Developed System and that of Meteorological Station Instrument. 
The results are analyzed using mean bias error (MBE). Table 1 shows the statistical results obtained by comparing the data obtained from standard commercial instrument and that of the developed system on a sunny day using MBE.

The MBE gives a measure of the difference between the estimators' expected value and the true value of the parameter being estimated, it is expressed by the following equation;

$$
\operatorname{MBE}=\sum \frac{\left(X_{\text {estimated }}-X_{\text {measure }}\right)^{2}}{N}
$$

Where $X_{\text {estimated }}$ the data is measured by the developed system,$X$ measuredis the obtained from the meteorological station and $N$ is the number of sample data.

After demonstrating the behavior and good accuracy of the sensors under harsh environmental conditions, then measurement of the parameters of a stand-alone PV system was conducted. The PV system panel was $120^{0}$ North-East direction at Bauchi, Nigeria (Long 10.28164; Lat 9.79096) on 23 ${ }^{\text {th }}$ March, 2016 from 6:00am to $6: 00 \mathrm{pm}$ which happens to be a sunny day.

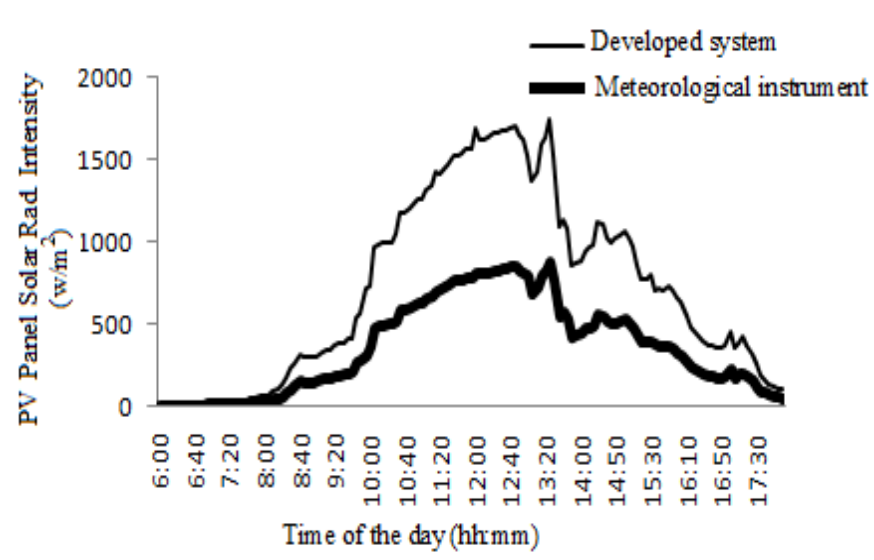

Fig. 8: One-day Profile of PV Panel Irradiance from the developed system and standard commercial instrument.

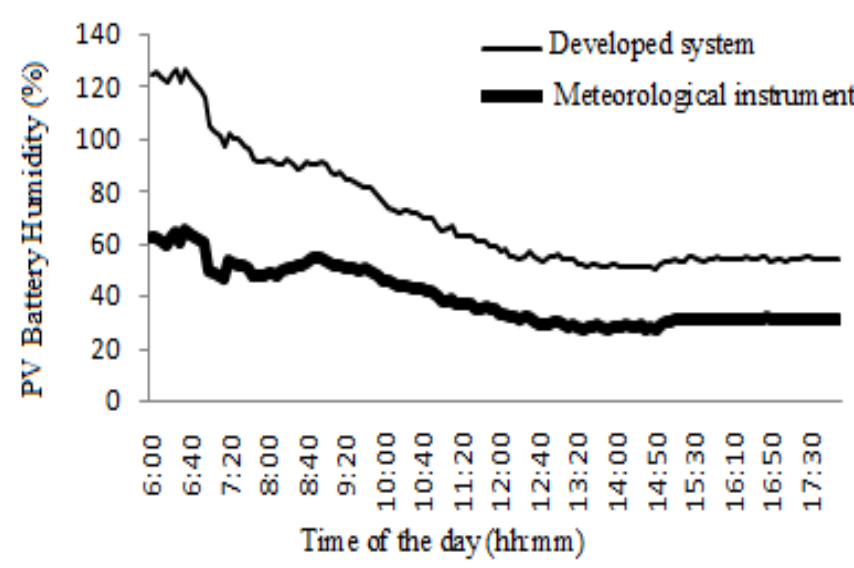

Fig. 10: One-day Profile of PV Battery Humidity from the developed system and standard commercial instrument.
Figs.: 8 to 11illustrate the results obtained from the developed system and standard commercial instrument.

Table 1: Mean Bias Error on Data Obtained from Developed System and that from Meteorological / Laboratory Instruments

\begin{tabular}{cc}
\hline Parameter & Mean Bias Error (MBE) \% \\
\hline Irradiance & 0.0432 \\
Temperature & 0.0412 \\
Humidity & -0.297 \\
Voltage & 0.024 \\
Current & 0.0182 \\
\hline
\end{tabular}

Fig. 8 shows the variation of the irradiance level, with the irradiance level at zero at 6:00, and increases to a max level of $900 \mathrm{~W} / \mathrm{m}^{2}$ at12:00 and also during the period 12:55 to 14:15. The increase in the irradiance level is not a steadily gradual one. The figure has many peaks; this is due to the fact that, in addition to the day the measurement was conducted being sunny it was also cloudy. This resulted in the moving clouds to interfere with the irradiation level.

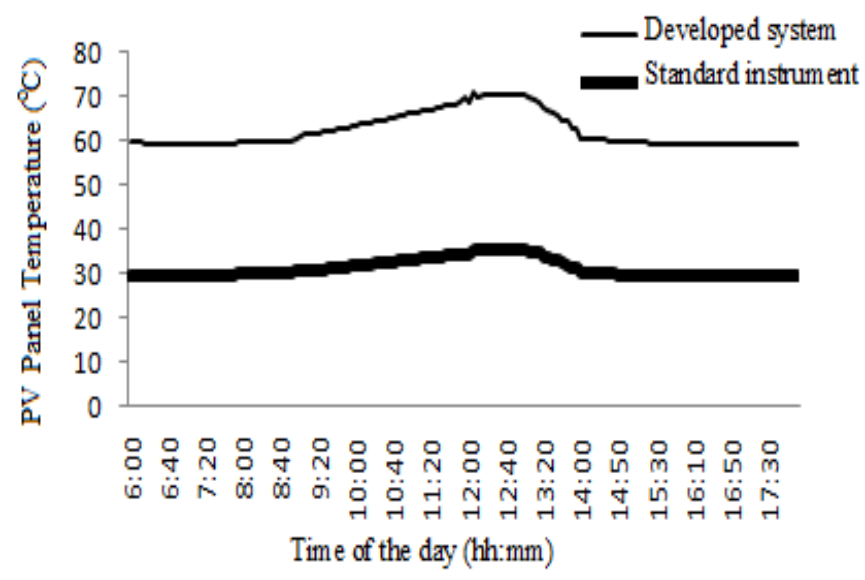

Fig 9: One-day Profile of PV Panel Temperature from the developed system and standard commercial instrument

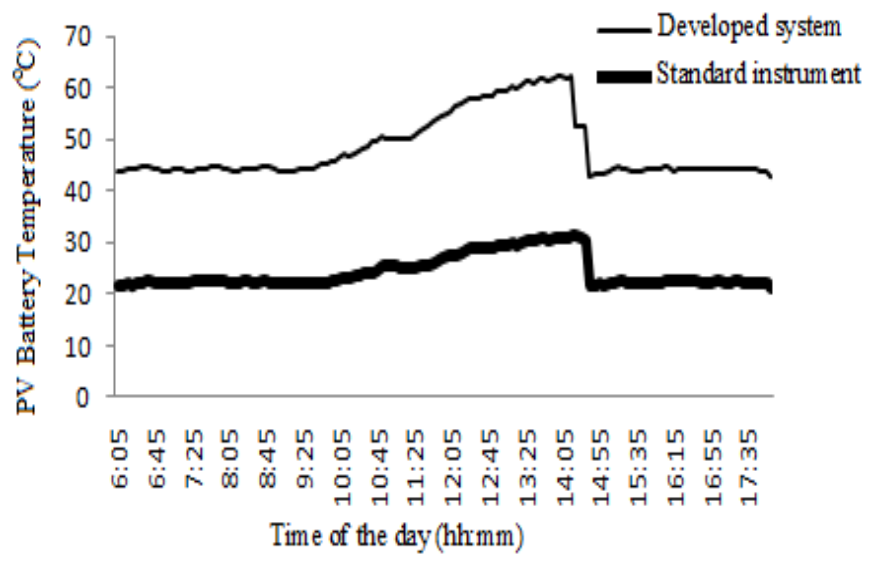

Fig 11: One-day Profile of PV Battery Temperature from the developed system and standard commercial instrument. 


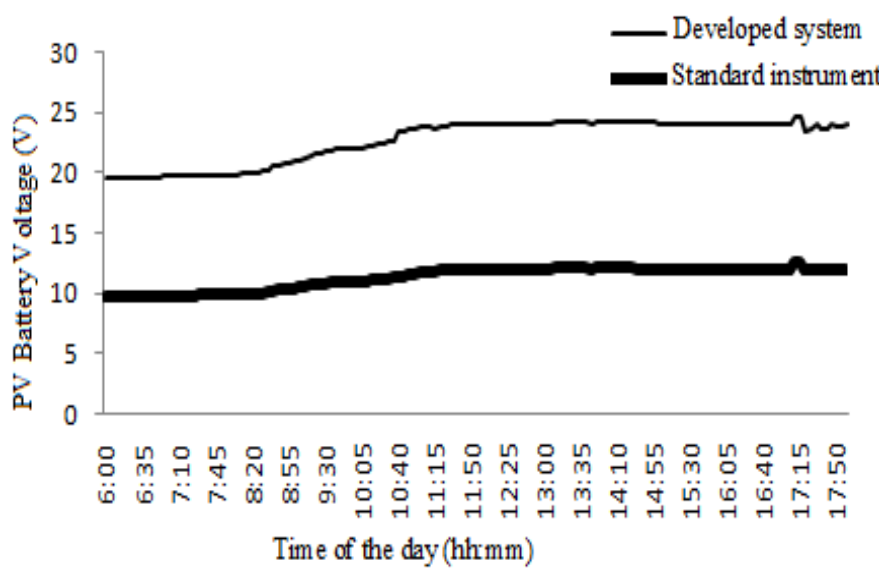

Fig 12: One-day Profile of PV Battery Voltage from the developed system and standard commercial instrument.

Fig. 9 shows the temperature profile of the PV panel. The temp $\left(30^{\circ}\right)$ of the panel was low during early morning (6:00) and increases exponentially to a max temp of $35.5^{\circ} \mathrm{C}$ between $12: 00$ and $13: 10$, and thereafter gradually decreases to $30^{\circ} \mathrm{C}$ at 17:00.

Fig. 10 indicates that humidity of the battery was high $(60 \%)$ at $6: 00$, it increases to a max value of $65 \%$ at $6: 45$. The humidity kept on decreasing thereafter and stabilized at 25\% level at 12:00.

The variation in the temp of the battery is relatively small as it varied between $26^{\circ} \mathrm{C}$ and $31^{\circ} \mathrm{C}$. The max temp of the battery occurred at 14:15 as shown in Fig. 11.

The battery voltage was $10 \mathrm{~V}$ as at $6: 00$ because the PV system worked during the previous night, resulting in the draining of the stored energy. However, as the irradiance level on the PV panel increases, the battery get charged and the voltage across the battery increases gradually to $12 \mathrm{~V}$ as at $11: 55$, and remains constant thereafter as shown in Fig. 12.

The loading profile on the PV system is relatively constant resulting in a current of approximately $5.7 \mathrm{~A}$ flowing as the load current as depicted in Fig. 13.

Based on the above discussions, it could be seen that as the irradiance level increases, the temp of both the panel and battery also increases, while the battery humidity decreases. Similarly, the battery gets charged and its voltage gradually increases and stabilized at $12 \mathrm{~V}$. As the sun sets, the irradiance level decreases and temp of both the panel and battery decreases, but the battery humidity remains fairly constant as from 12:00 upwards.

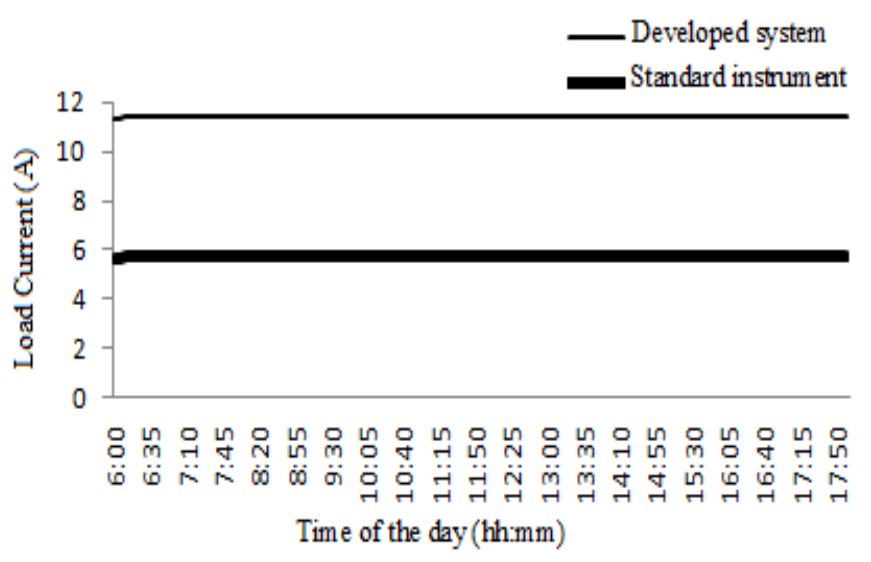

Fig 13: One-day Profile of PV Battery Load Current from the developed system and standard commercial instrument

\section{CONCLUSION}

A system meeting the accuracy requirements established by the IEC61724 standard related to photovoltaic monitoring systems was presented. The system design features include easy-to-obtain hardware, making it accessible to any researcher or user for the development of systems of their own design and use. This flexibility makes the system more suitable for each intended application such as the monitoring of PV plants and the collection of data at remote locations in developing countries.

From the experimental results obtained from the study, its shows that the parameters obtained using the developed system have good correlations with those obtained from standard commercial instruments used in meteorological stations and laboratory, with mean bias errors of $0.043 \%$ for solar radiation intensity channel, $0.0412 \%$ for temperature channel, $-0.297 \%$ for humidity measurement channel and $0.024 \%$ for PV battery voltage channel.

\section{REFERENCES}

[1] National Renewable Energy Laboratory, "Performance Parameters for Grid-Connected PV Systems", 1617 Cole Blvd., Golden, CO 804012 Arizona, 2005.

[2] Maheshwari, A. and Agarwal, V."Field Measurement of Photovoltaic Module Performance Using a Handy Tool", Journal of Energy Research, Vol. 1, No 1, pp 222-227. 2013.

[3] Van Dky, E., Gxasheka, A. and Meyer, E."Monitoring Current-Voltage Characteristics and Energy Output of Silicon Photovoltaic Modules", Renewable Energy Journal, Vol. 30, Number 1, pp 339-411, 2005. 
[4] Jordan, D. C. and Sarah R.K. "Photovoltaic Degradation Rates-an Analytical Review", J. Photo. Engnr., Vol. 2, Number 1, pp 520-516, 2001.

[5] Guizhong, W., Yan, D., Yuanlong, A. and Kaidong, G. "Performance Monitoring and Analysis of the Photovoltaic Power Generation System Based on the PCI Data Acquisition Card", Research Journal of Applied Sciences, Engineering and Technology, Vol. 3, Number 2, pp 495-501, 2014.

[6] Zahran, M., Atia1, Y., Alhosseen, A. and El-Sayed, I."Wired and Wireless Remote Control of Photovoltaic PV System”, .Journal of Energy, Vol. 5, Number 8, pp 656-666. 2010.

[7] Machacek, K., Benda, V. and Barinka, R. “Parameters of Photovoltaic Cells in Dependence on Irradiance and Temperature", .Journal of Energy, Vol. 30, Number 2, pp 840-844. 2013.

[8] Laurentiu, A., Alexandru, C. and Gheorghe, M. "Parameter Monitoring of Standalone Photovoltaic System", Int. Conference on electromechanical and Power Sys, Iasi, Romania, 8-9 October, pp. 18424805, 2009.

[9] Chokri, B. A., Kassas, M. and Ahmed, S."PVStandalone Monitoring System Performance Using Lab VIEW",. International Journal of Smart Grid and Clean Energy, Vol. 10, Number 1, pp 413-425, 2013.

[10] Parashar, S. and Dhankhar, S."Data Acquisition and Analysis of Solar Photovoltaic System”, Int. J. Inf. \& Comp. Tech., Vol. 14, Number 4, pp 1453-1458, 2014.

[11] Mark, W., Dougherty, B., David, L. and William, E. "Comparison of Photovoltaic Module Performance Measurement", National Institute of Standard Technology Journal, Vol. 3, Number 1, pp 128-159, 2006.

[12] Berberkis, S., Mather, P., Holmes, V. and Sibley, M. "Design of a Monitoring and Testing System for PV based Renewable Energy Systems", International Conference on Renewable Energy and Power Quality, Australia, 8 August, pp 28-272, 2010.
[13] Avishek, M., Alex, Z., McKay, K. and Ellul Alicia, E. "The Importance of Monitoring and Performance Analysis of a Rural Solar PV Electrification Project", Energy Journal, Vol. 2, Number 1, pp 16-23, 2009.

[14] Rosiek,S. and Batlles, F. "A Microcontroller-Based Data-Acquisition System for Meteorological Station Monitoring", Journal of Energy, Vol.49, Number 1, pp $3746-3754,2008$.

[15] Forero, N., Hemandez, J. and Gordillo, G. "Development of a Monitoring System for a PV Solar Plant”, Journal of Energy Conv. Managt., Vol. 47, Number 3, pp. 2329-2339, 2005.

[16] Alsan, S. M. and Reza, L. "Data Acquisition with LabVIEW", Journal of Energy, Vol.14, Number 4, pp 115-133, 2012.

[17] Bala, H. M., Siva, V., Satish, K., Ramakrishnan, C. and Sowjanya, E."PV Solar Cell Real Time Data Monitoring Using LabVIEW and DAQ", Int. J. Advance Research, Vol. 41, Number 2,pp 227 - 887, 2013.

[18] Koutroulis, E. and Kalaitzakis, K. "Development of Integrated Data-Acquisition for Renewable Sources System Monitoring", Journal of Renewable Energy, Vol. 28, Number 2, pp139-159, 2013.

[19] Fuentes, M., Vivar, M., Burgos, J., Aguilera, J. and Vacas, A. "Design of Accurate Low Cost Autonomous Data Logger for PV System Monitoring Using Arduino that Complies with IEC Standards", Journal of Solar Energy Mat. and Sol. Cells, Vol. 1, Number 2, pp 542-529, 2014.

[20] Shariff, F., Abdrahim, N. and Ping, H. W. "ZigbeeBased Data-Acquisition for Online Monitoring System", Journal Expert. Syst. with Appl. Vol. 42, Number 2, pp 1730-1742, 2015.

[21] Pietruszko, S. M. and Gradzki, M. "1-KW GridConnected PV System After Two Years Monitoring" International European Photovoltaic Solar Energy Conference and Exhibition, Europe,8 - 10, Nov., pp. 91-93, 2004. 